Association for Information Systems AIS Electronic Library (AISeL)

BLED 2005 Proceedings

BLED Proceedings

December 2005

\title{
Factors Affecting Evaluation of E-Business Projects
}

Dusan Lesjak

University of Primorska, Faculty of Management

Vasja Vehovar

University of Ljubljana, Faculty of Social Sciences

Follow this and additional works at: http://aisel.aisnet.org/bled2005

\section{Recommended Citation}

Lesjak, Dusan and Vehovar, Vasja, "Factors Affecting Evaluation of E-Business Projects" (2005). BLED 2005 Proceedings. 27. http://aisel.aisnet.org/bled2005/27

This material is brought to you by the BLED Proceedings at AIS Electronic Library (AISeL). It has been accepted for inclusion in BLED 2005

Proceedings by an authorized administrator of AIS Electronic Library (AISeL). For more information, please contact elibrary@aisnet.org. 


\title{
Factors Affecting Evaluation of E-Business Projects
}

\author{
Vasja Vehovar \\ University of Ljubljana, Faculty of Social Sciences, Slovenia \\ vasja.vehovar@uni-lj.si \\ Dušan Lesjak \\ University of Primorska, Faculty of Management, Slovenia \\ dušan.lesjak@fm-kp.si
}

\begin{abstract}
The 2003 survey among Slovenian companies was studying the factors affecting the formal evaluation of e-business projects. The corresponding causal model revealed that the perceptions and the attitudes towards e-business strongly affect the corresponding evaluation practice. In particular, the recognition of the needs for corresponding evaluation had the strongest effect. On the other hand, the high occurrence of problem related to e-business implementation has a negative impact on the introduction of the evaluation methods.
\end{abstract}

\section{Introduction}

Throughout the literature, e-business has often been studied from the technical (information and communication technology), organizational, managerial or legislative aspects, while there are fewer studies that deal with the economic aspects and with the corresponding evaluation. Nevertheless, the latter presents an important supplement to the former aspects, as it can provide an answer to most important questions related to the justification of the e-business investments and implementation (Hasan and Tibbits, 2000; Ngai and Gunasekaran 2004).

With some exceptions, the evaluation of e-business is a rarely researched topic (Chong, 2002; Cummings, 2004; Varian, 2002; Kleist, 2003; OECD, 2004). We investigate empirically in this paper how companies cope with the need for the evaluation of their ebusinesses. However, we narrow the scope to the issues related to whether and why companies introduce such evaluation. We thus not elaborate in the question of specific 
models developed for the evaluation itself, but we focus predominantly on types of evaluation approaches and the factors that affect their applications.

Within this challenging context, we have investigated how companies are dealing with the need for the evaluation of their e-businesses. However, due to the broadness of the problem, we have narrowed the scope of our research to the issues related to whether companies introduce such evaluation. We thus predominantly focus on different types of e-business evaluation approaches.

\section{Conceptual Framework}

Based upon the experience of the previous research (Kauffman and Walden, 2001; Plant, 2000; Green, 2002; Yap, 2002), we investigate here the factors affecting the practice of implementing the evaluation approaches for justifying e-business projects e-business projects, or the ICT intensity, the type of the company have any influence on evaluation methods?

Conceptually, we can structure the relationships in the following framework (Figure 1) taking into account the authors who deal with the e-business metrics (e.g. Jagannathan et al., 2001; Stern, 2002; Straub et al., 2002a, 2002b; Zhu and Kraemer, 2002) and other relevant literature which deal with approaches and indicators of successful e-business companies (e.g. Kleist, 2003; Ahmad et al., 2004) together with our own experience and findings (Lesjak et al., 2003).

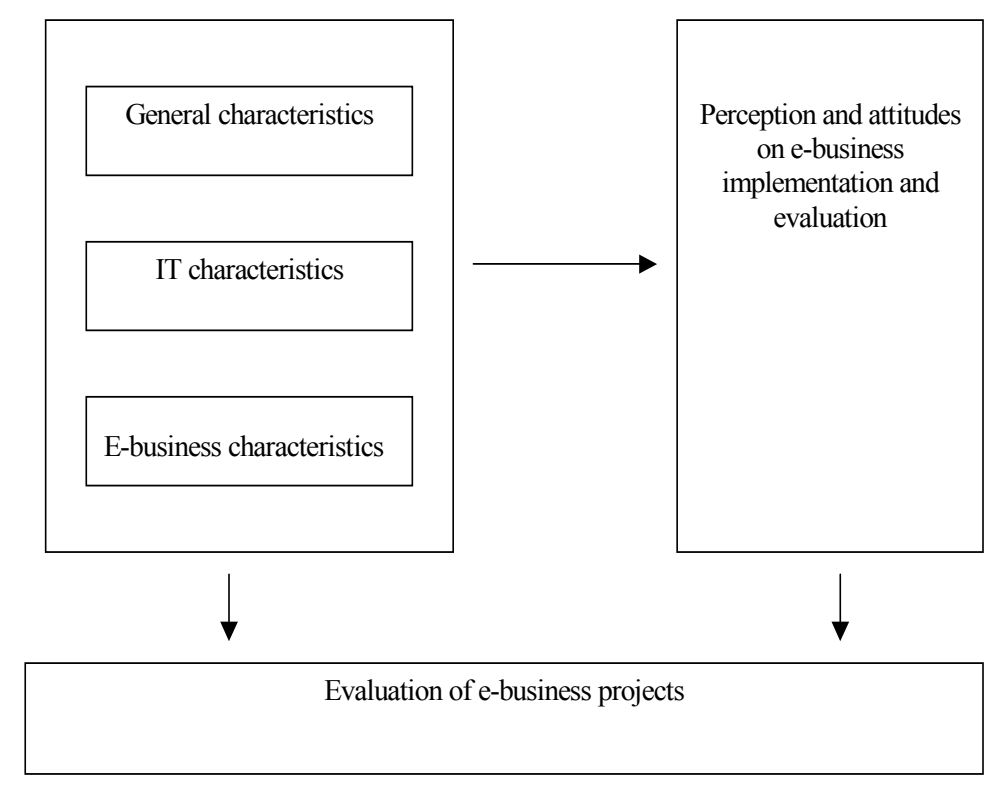

Figure 1: Conceptual framework for the factors affecting the evaluation of e-business projects

We are checking here the following:

- The IT developments strongly affect:

- the attitudes towards e-business, particularly the perception and understanding of its role in the company, 
- the usage of evaluation methods.

- However, we still expect a strong and independent role of the attitudes themselves on the implementation of more intensive formal evaluation approaches.

\section{The Data Collection}

The initial sampling frame was based on responding companies from December 2002 national representative RIS e-business survey $(n=1,260$, response rate $70 \%)$. The RIS research (http://www.ris.org) is performed annually since 1996 and presents a leading source for studying the trends in e-business and information society in Slovenia. The initial RIS 2002 sample was a representative sample of all Slovenian companies, however, the self-employees and home businesses were excluded (i.e. SOHO business).

The empirical survey research we present here was entirely devoted only to the issues of the evaluation of e-business projects and it was performed over the telephone in June 2003. Altogether 1,112 companies were contacted. The IT responsible persons were the target responding units, while for the smallest companies the directors or owners were addressed.

In total, 755 companies responded. As usual, the response rate was much higher among large companies. Out of 755 some 335 companies report sizeable e-business project that exceeds 4000 Euros. With these companies, we were interested in the formal evaluation methods for their e-business undertakings.

Table 1: Methods for evaluating e-business projects

\begin{tabular}{|l|c|c|}
\hline \multicolumn{1}{|c|}{ Usage of some formal evaluation methods } & $\mathrm{n}$ & $\%$ \\
\hline Use some methods & 45 & 13.4 \\
\hline In preparation to use & 11 & 3.3 \\
\hline Plan to use in next 12 months & 16 & 4.8 \\
\hline Thinking about usage & 40 & 11.9 \\
\hline Have not thought about usage yet & 223 & 66.6 \\
\hline Total & 335 & 100.0 \\
\hline
\end{tabular}

Companies were estimating general attitudes and perception towards their e-business implementation, as well the attitudes towards the evaluation procedures. The respondents rated their agreement on a five-category ordinal scale from 1 (totally disagree) to 5 (totally agree).

We analyzed the above statements also with the factor analysis. Two factors appeared, each explaining around $40 \%$ of the variance:

- Factor 1 expresses the general satisfaction with e-business projects (shadowed),

- Factor 2 is related to the presence of high need for the evaluation of e-business projects. 
Table 2: Attitudes on implementation of e-business projects

\begin{tabular}{|l|c|}
\hline \multicolumn{1}{|c|}{ statements } & mean \\
\hline Our company is satisfied with the economic impacts of e-business & 3.6 \\
\hline E-business usage increases satisfaction among all participants in the process & 3.6 \\
\hline Our company is satisfied with the procedures for the evaluation of e-business projects. & 3.0 \\
\hline Impacts of e-business are so obvious that there is no need for their evaluation & 3.3 \\
\hline $\begin{array}{l}\text { There is lack of knowledge and information on evaluation of e-business projects in our } \\
\text { company }\end{array}$ & 3.3 \\
\hline Our management demands financial evaluation of e-business related investments. & 3.2 \\
\hline
\end{tabular}

Similarly to the items related to the perception of the e-business, we also measured the perception of the problems companies encounter in their e-business implementation. High score denotes that companies encounter the corresponding problem.

Table 3: Attitudes towards the e-business project evaluation problems

\begin{tabular}{|l|c|}
\hline \multicolumn{1}{|c|}{ Statements } & Mean \\
\hline Lack of time for the evaluation & 3.3 \\
\hline Lack of knowledge on evaluation & 3.0 \\
\hline Problems with subcontractors & 2.9 \\
\hline Problems with educating users & 2.9 \\
\hline Prolongation of the project & 2.9 \\
\hline Exceeding of the planned costs & 3.1 \\
\hline Problems with the measurements of effects of e-business projects & 3.1 \\
\hline
\end{tabular}

The corresponding factor analysis aggregated the above attitudes into two dimensions:

- Factor 1 is related to the problems of the e-business implementation (shadowed),

- Factor 2 is related to the good planning and formalizing of e-business projects. Negative values thus denote here the weakness in this aspect. We should add that the variables that characterize Factor 2 also have high loadings on Factor 1.

\section{The Structural Equation Model}

Very often in social and economic research, the variables are inter-correlated in a relatively complicated manner. The multivariate approach, which treats all variables simultaneously, is thus necessary to reveal the underlying structure of the data.

As we study here the causal relations among the variables outlined in the conceptual framework (Figure 1), we employed the structural equation model approach.

We measure the concepts from the Figure 1 with the following variables:

Characteristics of the company. The observed variables, which arise from 13 items related to the basic characteristics of the companies, are structured into three segments: general characteristics of the company, ICT infrastructure characteristics and e-business characteristics. 
Some of these items were further linearly combined, so we measure the three aspects with following five variables:

- SIZE: Size of the company according to the official classification;

- N_EMPLOY: Number of persons employed in an organization. We used logarithmic transformation of the variable;

- IT: IT uptake was calculated as an average of PC/employee ratio and percentage of Internet users among employees. We used logarithmic transformation of the variable;

- NPROJECT: Number of sizeable e-business projects;

- $\quad$ EB_VAR: Number of different types of e-business projects (B2E, B2C, B2A, B2B).

Perception and attitudes on e-business implementation and evaluation. These intervenient variables were based on four factors from attitudinal measurements:

- two dimensions of the attitudes on implementation of e-business:

- EV_SATIS: satisfaction with e-business (Factor 1 in the Table 2),

- EV_NEED: need of e-business evaluation (factor 2 in the Table 2);

- two dimensions of the attitudes on e-business implementation problems:

- EB_PROBL: implementation problems (Factor 1 in the Table 3),

- EB_PLAN: well planned e-projects (Factor 2 in the Table 3).

Usage of the evaluation. The key dependant variable was the level of implementation of evaluation procedures (Table 1), where the category of companies actually using some evaluation procedures was additionally structured. We thus have (EVAL_INV): degree of involvement into e-business evaluation.

The model was estimated by normal theory maximum likelihood using the LISREL 8.51 program (Jöreskog et al., 2000). For structural equation models it is assumed that variables are at least approximately normally distributed. This was not entirely satisfied in our case, as some of the variables were strongly skewed. For skewed distributions we applied the usual remedy for this problem, i.e. the logarithmic transformation. With the remaining discrepancies we refer to several studies indicating high robustness of these models regarding the assumption of normality (e.g. Boomsma and Hoogland, 2001).

The causal models have the standard diagnosis expressed with $\chi^{2}$ statistics and corresponding $p$-value. The $p$-value is typically requested to be above $p=0.05$ and preferable closer to $p=0.5$, so that the model cannot be rejected.

Another important measure to evaluate these models is the $\boldsymbol{R M S E A}$ value. According to Saurina and Coenders (2002: 222-223) the standardized $\chi^{2}$ test of the hypothesis of perfect fit to the population covariance matrix (i.e. the $p$-value) should be given less importance than the measures of the degree of approximation between the model and the population covariance matrix. The Root Mean Squared Error of Approximation (RMSEA) is typically used for this. Values equal to 0.05 or lower are generally considered to be acceptable (Browne \& Cudeck, 1993).

The standardized regression coefficients, which are usually labeled over the arrows in the path diagram, are also extremely important for the interpretation. For example, the value 0.25 of this coefficient means that the change in one standard deviation of the independent variable causes an increase that can be expressed as 0.25 of the standard 
value in the dependant variable. Typically, the corresponding t-values larger than 1.96 denote a strong causal relation among variables.

The path diagram for our model is depicted in Figure 2. We assume that the causal order basically flows from the observed characteristics of the companies to intervenient variables: implementation problems (EB_PROBL), planning of the e-business (EB_PLAN), satisfaction with e-business (EB_SATIS), and also to the need of e-business evaluation (EV_NEED).

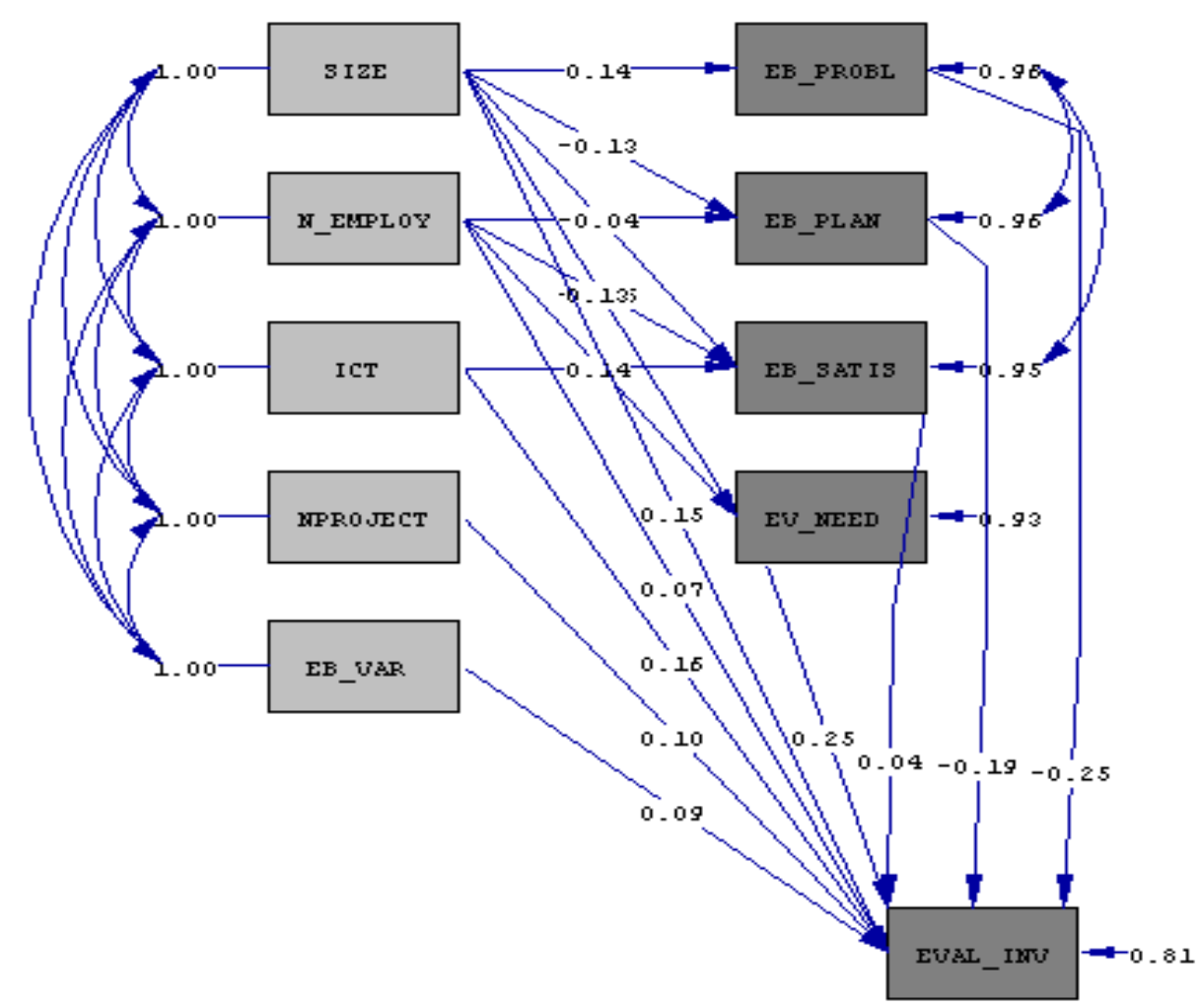

Chi-square=22.34, $d f=16, \quad P-v a l u e=0.13266$, RMSEA=0.042

Figure 2: Path diagram with standardized values of the estimates for the causal effects

Of course, according to the conceptual framework (Figure 1), all abovementioned variables should also affect the degree of evaluation involvement (EVAL_INV).

The path diagram in Figure 2 shows the standardized regression coefficients and also the standardized effects of the unexplained variances (the short arrows pointing to the variables). As these latter values are relatively high, this denotes substantial level of the variability that remained unexplained. However, the proportion of the unexplained variance for the target variable (EVAL_INV) has the value of 0.81 , what is acceptable. Even more, such a value is much above usual expectations for this type of problems, where the attitudes are involved. Of course, the proportions of the unexplained variance for the intervenient variables are much higher. We have value 0.93 for the problems with e-business (EB_PROBL), which was particularly strongly influenced by the size of the company (SIZE) with the standardized regression coefficient of $0.14(\mathrm{t}=2.07)$. The other three intervenient variables also have the similarly high values for the share of 
unexplained variance (0.95). These high proportions of the unexplained variances for the intervenient variables somehow confirm observation from previous section: the attitudes show relatively little variation across the control variables.

The model has good explanation power according to the standard diagnostics. The RMSEA of the model is 0.042 , which indicates acceptable fit of the model. The $p$-value $(0.13)$ is also considerably high and suggests that the model cannot be rejected.

The model also reports on the strength of relation among observed variables themselves and also among the intervenient ones. The corresponding arrow links can be found in the Figure 2, however, the related correlation coefficients are omitted from the diagram for the sake of simplicity and predominantly also because values were not so high. The only exception is the high negative value of the correlation $(-0.70)$, between the two factors (EB_PROBL and EB_PLAN) of "problems with implementation of e-business" (Table 11). We should add that this was also an observation at the end of previous section, where we mentioned the specific pattern of the scatter-plot, when drawing the companies into the space of these two factors.

With respect to the impact of the observed and intervenient variables on the key target dependant variable (EVAL_INV) we can summarize the following:

- As expected, a strongly articulated need for the evaluation (EV_NEED) also increases the actual evaluation of e-business project; we can observe here the strongest causal link in the whole model, with the value $0.25(\mathrm{t}=3.96)$.

- Problems with the implementation of e-business (EB_PROBL) and with the corresponding planning (EB_PLAN) reduce the e-business evaluation involvement, as their standardized coefficients take high negative values, $-0.25(\mathrm{t}=-2.71)$ and $-0.19(\mathrm{t}=-$ 2.13) respectively. Here we should add that the high perception of the problems related to the e-business implementation (EB_PROBL) also moderately decreases the satisfaction with e-business (EB_SATIS). The corresponding arrow link can be found in the Figure 2, while the correlation value $(-0.12)$ is not explicitly labeled in the Figure 2.

- Higher satisfaction (EB_SATIS) with e-business shows only a slight tendency to stimulate the evaluation involvement (EVAL_INV). The corresponding value 0.04 of the standardized regression coefficient is positive, although it is not statistically significant $(\mathrm{t}=0.61)$.

- The impact of the basic observed variables on the dependant variable is generally not significant. Nevertheless, the signs and the direction of the causal links are logical and expected. The role of IT infrastructure seems to be far the strongest among them, with the standardized value of 0.16 , which is also very close to the usual significance level $(\mathrm{t}=1.88)$. The number of employees (N_EMPLOY) has the lowest effect with 0.07 $(\mathrm{t}=0.47)$, while the number (NPROJECT) and the variety (EB_VAR) of the projects have moderate values around $0.10(\mathrm{t}=1.55)$. Similar is true for the impact of the size of the company (SIZE), with the value $0.15(\mathrm{t}=1.23)$. We can speculate here that with a slightly increased sample size, some of these links would also become statistically significant at standard significance level $(t=1.96, p=0.05)$.

- Some other links where removed from the model, because the corresponding standardized coefficients were around zero and they were not statistically significant, so they do not contribute to the model.

- The size of the largest project was not included into the model due to the cumulative effects of high item nonresponse. The problems with this variable are regrettable, because indices from bivariate analysis show that it actually has a relatively effect, similar to the variable related to the size of the companies. 


\section{Conclusion}

We investigate in this paper how companies are coping with the evaluation of e-business projects. We developed a conceptual model for the factors affecting the use of formal evaluation methods and we verified this model on a representative survey among Slovenian companies.

It is somehow surprising that the basic characteristics of the company have a relatively limited role on the usage of evaluation for e-business projects. Still, the high IT intensity seems to have the strongest direct impact among them. The size of the company has larger indirect effects than the direct ones. As a consequence, in the multivariate settings it is less important than in the bivariate analysis.

The findings from the causal model confirmed that the degree of the evaluation involvement is explained mostly by perception of the problems related to e-business and with the attitudes towards e-business evaluation, and not so much by the characteristics of the organization and the characteristics of the e-business project.

The attitudes towards e-business implementation and evaluation thus play the key important role on the actual usage of evaluation procedures. It is important to note that experience of the problems with e-business implementation has a negative role, while the satisfaction with e-business and the recognized need for evaluation have positive impact on the practice of e-business evaluation.

The high negative role of the perceived problems with e-business implementation deserves a special interpretation. Why would the high experience of the problems lower the tendency to adopt solutions to these problems? In search for this answer we follow the indirect effect via the satisfaction, as it may indicate the proper signs of the relations. Of course, more problems with e-business decrease corresponding satisfaction, while it seems to be the high satisfaction that increases the evaluation involvement. Consequently, the problems with e-business implementation also decrease the evaluation involvement.

With that we now face another relation to explain: where is the positive relation between satisfaction of e-business and the corresponding evaluation practice coming from? This question is particularly important, because almost half of the companies agree that evaluation is redundant due to obvious success and satisfaction with e-business project. We can speculate here that there actually exist another underlying latent variable, which can be labeled as "advanced understanding and implementation of e-business". Companies with high level on this variable provide complete and proper treatment for their e-business projects, from planning and formalization to evaluation stage. They also provide successful and satisfactory e-business implementation. The companies, which are high on this scale, thus have both, high satisfaction with e-business and also high involvement in evaluation procedures. Unfortunately, in the design stage of the survey, these relations were not yet that clear, so the measurement instrument was not developed to further elaborate this issue.

In any case, this research demonstrated extremely important role that the attitudes and perception of e-business have on implementation of e-business evaluation procedures.

Another measurement problem in this empirical study relates to the indicators for the size of the projects, what was not measured entirely successfully. As a consequence, it could not be included into the causal model. This presents no doubt another weakness of the model. Nevertheless, due to the high correlation with the size of the companies, we can still assume that the major loss in the model did not occur.

In future, the research on factors affecting the application of e-business evaluation should: 
- elaborate the measurement instrument to capture the IT component in much more wide and detailed aspects,

- improve the measuring of the size of the project, together with more specific location in time characteristics,

- expand the model to measure the latent variable, which would denote the general level of the understanding and elaboration of e-business project in the company.

The results also touch the general questions related to the evaluation and justification of e-business projects, particularly the discrepancy among a relatively high need for using formal evaluation methods and the limited practice of such evaluation. On one hand, when evaluating e-business projects the traditional assessments of investment cannot be used, because permanent change and a variety of qualitative and indirect benefits prevent the applications of the corresponding financial models. On the other hand, however, the actual evaluation methods may be truly inadequate and their results may actually not be worth of the efforts.

From a more substantial point of view, the research is thus needed to evaluate the effectiveness of e-business evaluation methods. How useful was the application of a certain evaluation approach? Are these approaches generally not used because they are ineffective? Or, they are useful, but they are not used, because of the ignorance of the potential users? Or, do the players in e-business implementation systematically avoid the forma evaluation?

Nevertheless, our results show that there exists a clear need for more elaborated evaluation procedures. Combined with dominant lack of their usage, we can basically point to the insufficiency of the existing methods The use of traditional methods should be thus at least combined qualitative approaches (e.g. Kleist, 2003), together with Delphi studies, SWOT analysis, etc. if not substituted with new promising methods such as Portfolio method (Chong, 2002), Loyalty Value Added methodology (Greengard, 2000; OECD, 1999), Benchmarking method (E-Commerce Benchmarks, 2001) and Balanced Scorecard (e.g. Martinsons et al., 1999; Hasan and Tibbits, 2002).

\section{References}

Ahmad, F., Razak, A. and Bakar, A.A., (2004): "Determining Success Indicators of ECommerce Companies Using Rough Set Approach", Journal of American Academy of Business, Vol. 5 No. 1/2, September, pp. 64 - 69.

Boomsma, A. and Hoogland, J.J., (2001), "The Robustness of LISREL Modeling Revisited" in Cudeck, R., Du Toit, S. and Sörbom, D. (Eds.), Structural Equation Models: Present and future. A Festschrift in honor of Karl Jöreskog, Scientific Software International, Chicago, pp. 139 - 168, available at: www.ppsw.rug.nl/ boomsma/ssi.pdf (accessed 1 September 2004).

Chong, Y.Y., (2002): Delivering on Your e-Promise: Managing e-Business Projects, available at: http://vig.pearsoned.com/store/product/1,3498,store.html, (accessed 3 April 2002).

Cummings, J., (2001): “The e-comm ROI squeeze”, Network World, 26 February.

Green, S., (2002): Profit on the Web, Axon Computertime, Auckland, New Zealand.

Greengard, S., (2000): Rethinking the Cost-Benefit Equation, BusinessFinanceMag, March. 
Hasan, H. and Tibbits, H.R., (2000): "Strategic management of electronic commerce: an adaptation of the balanced scorecard", Internet Research, Vol. 10 No. 5, pp. 439 450 .

Jagannathan, S. et al., (2001): Internet Commerce Metrics, Prentice Hall, Upper Saddle River, NJ.

Jöreskog, K.G., Sörbom, D., Du Toit, S., (2000): LISREL 8: New Statistical Features, Lincolnwood: Scientific Software International.

Kauffman, J.R. and Walden, A.E., (2001): "Economics and Electronic Commerce: Survey and Directions for Research", International Journal of Electronic Commerce, Vol. 5 No. 4, Summer, pp. 5.

Kleist, V.F., (2003): "An approach to Evaluating E-Business Information System Projects”, Information Systems Frontiers, Vol. 5 No. 3, pp. 249 - 263.

Lesjak, D., Vehovar, V., Seymour, T., Sulčič, V., (2003): "Economic Evaluation and Justification of e-business (Project) in Slovenia", Issues in Information Systems, Vol. 4 No. 2, pp. 549 - 555.

Martinsons, M., Davison, R., Tse, D., (1999): "The balanced scorecard: a foundation for the strategic management of information systems", Decision Support Systems, Vol. 25, pp. $71-88$.

Ngai, E.W.T. and Gunasekaran, A., (2004): Implementation of EDI in Honk Kong: An Empirical Analysis, Industrial Management \& Data System, Volume 104, Number 1, pp. 88 - 100.

OECD (2004): The Economic Impact of ICT - Measurement, Evidence and Implications, OECD Publications, Paris.

Plant, R.T.E., (2000): E-Commerce: Formulation of Strategy, Prentice Hall, Upper Saddle River, NJ.

RIS, (2003): Podjetja, e-poslovanje, available at: www.sisplet.org/ris/ris/vnosi/Upload/uploadFiles/eposlovanje1.pdf (accessed 15 July 2003).

Saurina, C. and Coenders, G., (2002): "Predicting Overall Service Quality. A structural Equation Modelling Approach" in Ferligoj, A. and Mrvar, A. (Eds.), Developments in Social Scence Methodology, zbirka Metodološki zvezki, Vol. 18, pp. 217-238, available at:

http://mrvar.fdv.uni-lj.si/pub/mz/mz18/coender2.pdf (accessed 1 September 2004).

Stern, J., (2002): Web Metrics: Proven Methods for Measuring Web Site Success, John Wiley\&Sons, New York.

Varian R.H., (2002): Netting a Profit.Optimize Magazine, Financial Management, May 2002, available at: www.optimizemag.com/issue/007/pr financial.htm (accessed 10 May 2002).

Yap, E., (2002): "Seven Keys to Successful e-Business", MIS Asia, March, pp. 45 - 53.

Zhu, K. and Kraemer, K., (2002): "E-Commerce Metrics for Net Enhanced Organizations: Assessing the Value of E-commerce to Firm Performance in the Manufacturing Sector", Information Systems Research, September, pp. 275 295. 